\title{
Correction to: Prevalence and predictors of burnout among obstetrics and gynecology residents in Canada
}

\author{
Na'ama O. Al-Ma'mari, Ashley I. Naimi and Togas Tulandi
}

\section{Correction}

Following the publication of this article [1], the authors have removed the "Maslach Burnout Inventory, Forms: General Survey, Human Services Survey \& Educators Survey" from the supplementary materials of the article [1] due to copyright restrictions.

Received: 23 April 2018 Accepted: 23 April 2018

Published online: 22 May 2018

\section{Reference}

1. Al-Ma'mari et al (2016) Prevalence and predictors of burnout among obstetrics and gynecology residents in Canada. Gynecol Surg 13:323. https://doi.org/10.1007/s10397-016-0955-3

\footnotetext{
* Correspondence: togas.tulandi@mcgill.ca

The original article can be found online at https://doi.org/10.1007/s10397016-0955-3

Department of Obstetrics and Gynecology, McGill University, 1001 Boulevard Decarie, Montreal, QC H4A 3J1, Canada
} 